\title{
Gem-Diphosphonates: The Motif of Diverse Biological and Medicinal Importance
}

\author{
Wafaa Abdou and Reham Barghash \\ Division of Chemical Industries Research, National Research Center, Dokki, Cairo 12311, Egypt
}

\begin{abstract}
The introduction of gem-diphosphonates (known as bisphosphonates, BPs) in oncology has dramatically changed the management of patients with metastatic bone disease. In this manuscript, we thoroughly scrutinize the available body of clinical trials supporting the use of bisphosphonates in this setting and review new and ongoing research. Additionally, we summarize the data showing the benefits of BP-use in the prevention of treatment-induced bone loss and the intriguing emerging evidence on the antitumor potential of some of these agents when used in the adjuvant setting. Finally, we address the need for a careful consideration of potential benefits of BPs therapy and the risk for osteonecrosis, a recently recognized late-toxicity of their use.
\end{abstract}

Key words: Bisphosphonates, cell adhesion, palliative care, adjuvant drug therapy, osteonecrosis, anti-tumor agents.

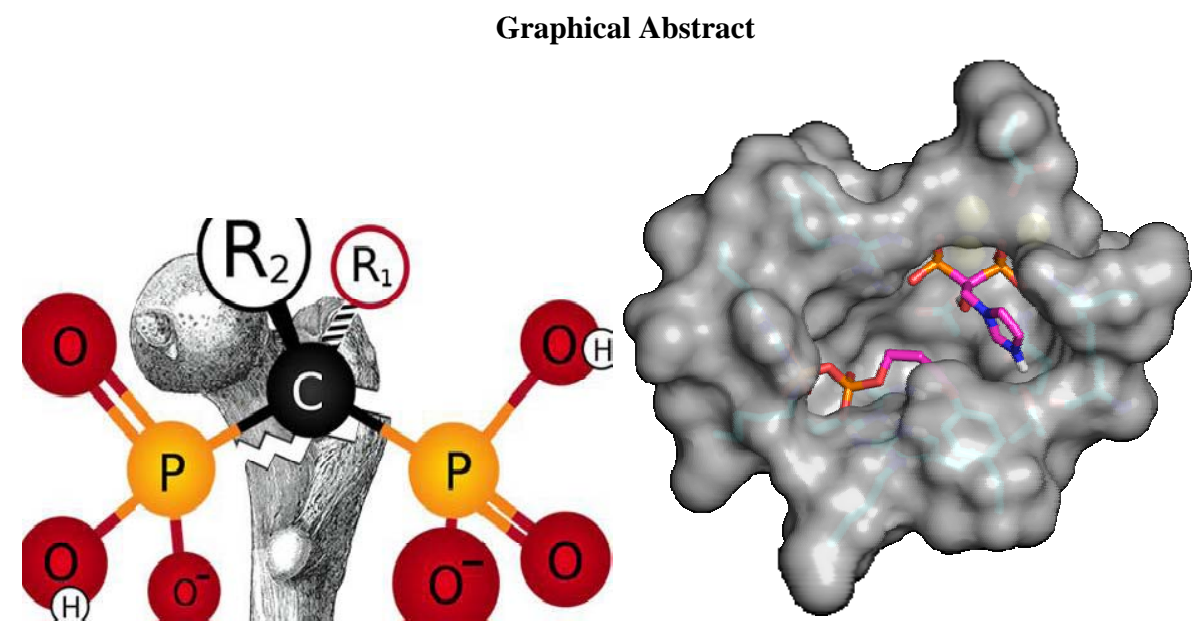

\section{Introduction}

Recently, the 40th anniversary of the publication of a landmark paper by Herbert Fleisch and colleagues in 1968 passed, describing the in vitro and in vivo influence of bisphosphonates-erroneously called diphosphonates at that time - on the precipitation and dissolution of calcium phosphate $[1,2]$. This research paved the way to the study of the effects of these agents on hydroxyapatite, and their first therapeutic application in a patient with myositis ossificans just

Corresponding author: Abdou Wafaa, Ph.D., professor, research field: biophosphorus chemistry. E-mail: wabdou@link.net. one year later $[3,4]$.

BPs are synthetic organic compounds characterized by a backbone P-C-P group. So, they are chemically stable analogs of naturally occurring inorganic PPs (pyrophosphates) (Fig. 1). In contrast of PPS, BPs are resistant to break down by enzymatic hydrolysis. BPs (Bisphosphonates) were developed in 1865 and were first used as herbicides, water softeners, soften water in irrigation systems used in orange groves, detergents and toothpaste additives. However, BPs were investigated for the first time in the 1960s in disorders of bone metabolism. In recent years, 1980's BPs are well established in pharma as a major class of drugs for the treatment of bone diseases. 


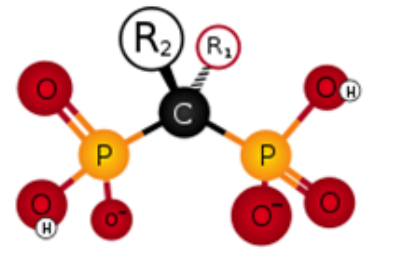

BPs (Bisphosphonates)

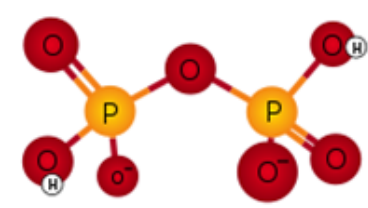

PPs (Pyrophosphates)

Fig. 1 General formula of BPs (bisphosphonates) and PPs (pyrophosphates).

Although our bone seems solid and stable, they actually undergo constant renewal. Specialized cells called osteoclasts draw used calcium out of bone while other cells called osteoblasts replace it. In some instances, e.g. after the menopause, this process can get out of balance. Calcium starts to leach out of bones faster than it can be replaced leading to a brittle-bone disease called osteoporosis (Figs. 2 and 3). BP-drugs compact this problem by reducing the activity of osteoclast and slow the loss of calcium from bone. So, it is prescribed for menopausal women both to prevent osteoporosis and to strengthen the bones. It is also used in the treatment of hypercalcemia resulting from therapy with steroid medications... etc. BPs potently inhibit osteoclast formation and bone resorption regardless of pathogenetic stimulus. They potently inhibit bone resorption in a variety of models of benign and/or malignant bone diseases irrespective of tumor types; preserves bone architecture and strength; novel anti-angiogenic and anti-pain effects; and reduces the number and size of bone metastases in models of tumor-induced osteoloysis.

Several studies indicate that BPs can be classified into at least two groups with different modes of action. BPs that most closely resemble pyrophosphate (such as clodronate and etidronate) can be metabolically incorporated into the phosphate chain of ATP-containing compounds so that they become non-hydrolysable. The P-C-P-containing ATP-analogs inhibit cell function and may lead to apoptosis and death of osteoclasts. The more potent, nitrogen-containing BPs (such as pamidronate, and risedronate) are not metabolized in this way but they act, directly on liver enzymes (especially GTPases) that lead to the loss of osteoclast activity and induction of apoptosis (Fig. 4). These different modes of action might account for subtle

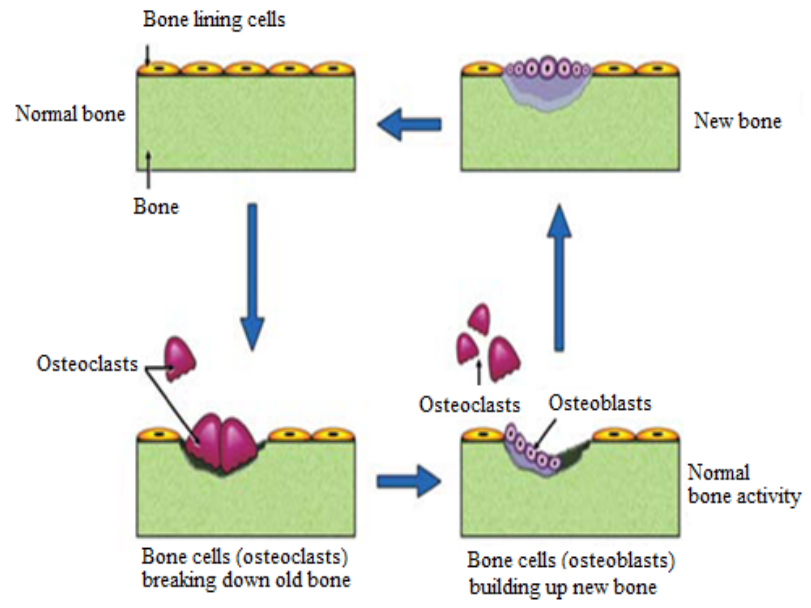

Fig. 2 Proposed mode of normal action of BPs.

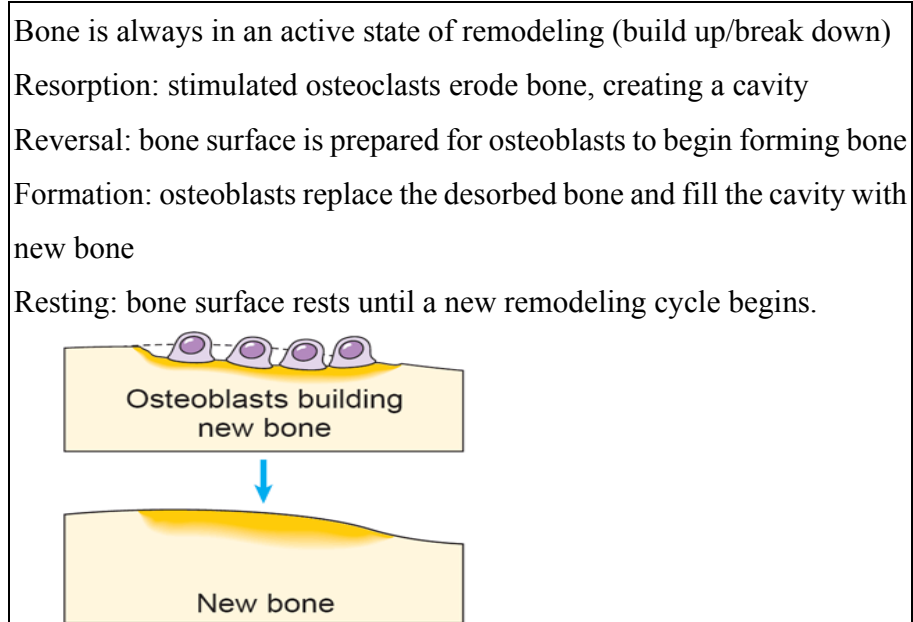

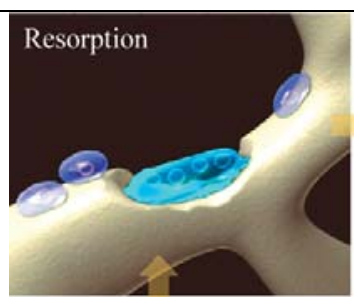

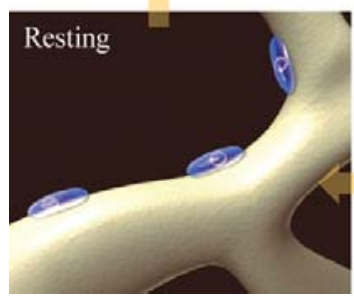

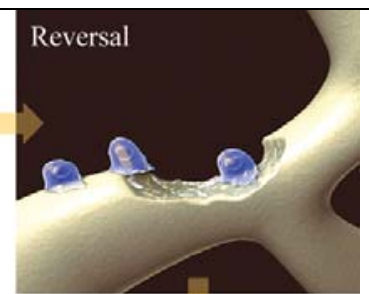

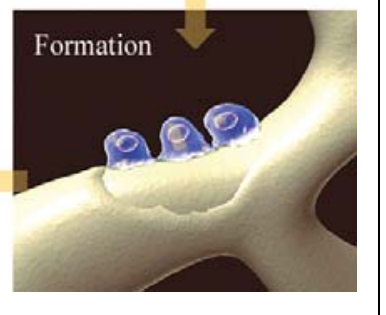

Fig. 3 Normal Bone Biology (Diagram showing bone remodeling, Cancer Help UK). 
<smiles>O=P([O-])([O-])C(Cl)(Cl)P(=O)([O-])[O-]</smiles>

(Dichloromethylene)-bisphosphonate (Clodronate)<smiles>O=P([O-])([O-])C(O)(Cc1cccnc1)P(=O)([O-])[O-]</smiles>

(1-Hydroxy-2-(3-pyridene)bisphosphonate (Risedronate)<smiles>CC(O)(P(=O)([O-])[O-])P(=O)([O-])[O-]</smiles>

(1-Hydroxyethylidene)ene)bis-phosphonate (Etidronate)<smiles>NCC(O)(P(=O)([O-])[O-])P(=O)([O-])O</smiles>

(3-Amino-1-hydroxypropylidene)bisphosphonate (Pamidronate)

Fig. 4 Some examples.

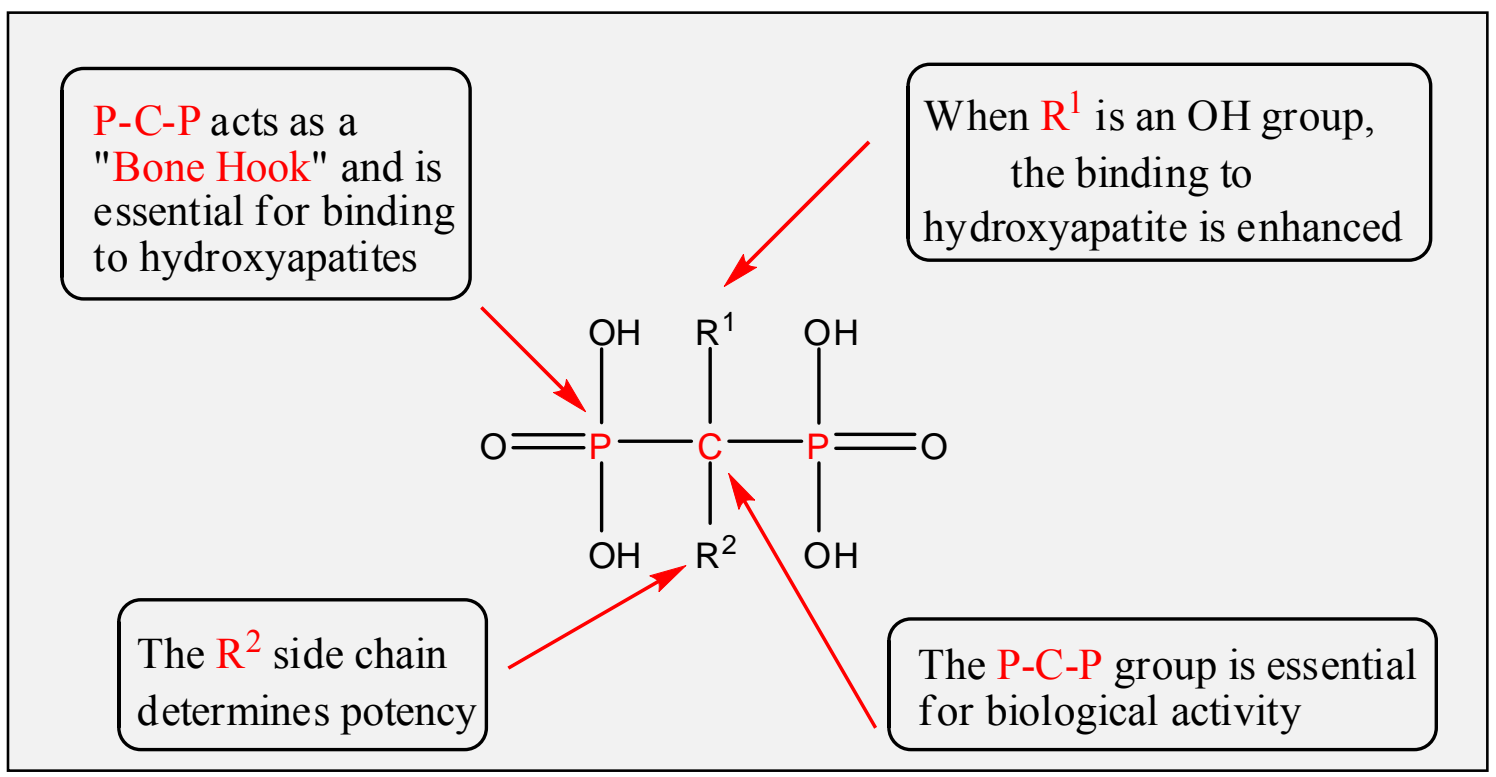

Fig. 5 Structural-activity relationship.

differences between compounds in terms of their clinical effects [4]. Recently, the third generation of $N$-MBPs that contain free nitrogen moiety as one of the side chain has recognized high bone specificity of [5].

This unique class of compounds of BPs shows a vast range of structure types and has potential applications in diverse therapeutic areas that involve microbial [6, 7], parasitic [8], herbicidal [9], viral (HIV) [10, 11], antiinflammation [12, 13], rheumatoid arthritis [13-15], and cancer diseases (Fig. 6) [16-19]. However, all BPs are similar in terms to their inhibitory effects on bone resorption, but seem to have different effects on other 


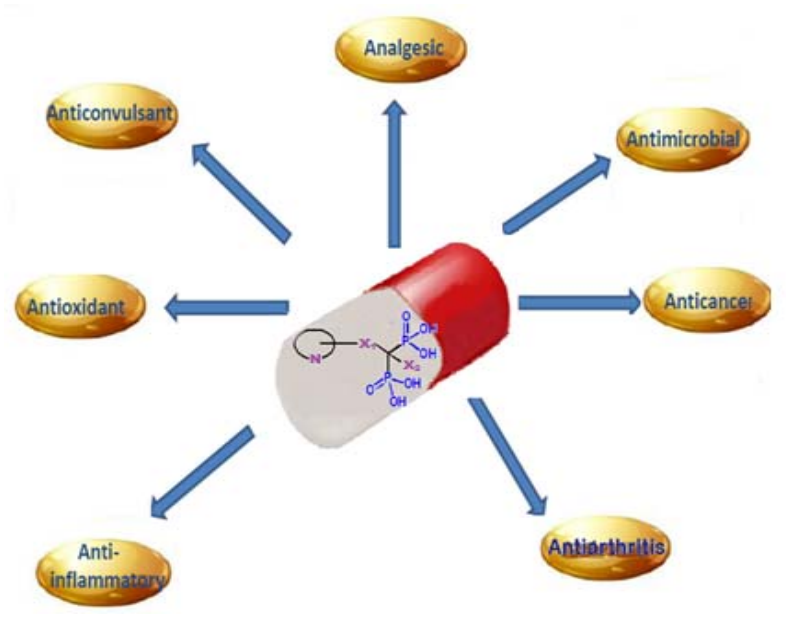

Fig. 6 BPs in pharmacology.

pathogens, in this review article, we are only focusing on the role of BPs in oncology.

\section{Pharmacology}

\subsection{Role of BPs in Oncology}

In oncology, the introduction of bisphosphonate therapy has radically improved the management and prevention of SREs (skeletal-related events) associated with malignancy disseminated to the bones, including pathologic fractures, bone pain, impaired mobility, spinal cord compression, and hypercalcemia (Fig. 7) [20, 21]. Thus the main actions of BPs can be summarizing as follows (Table 1 and Fig. 7):

Regulate high levels the human enzymes farnesyl hFPPS (pyrophosphate synthase) and hGGPPS (Geranyl-geranyl pyrophosphate synthase).

Act on Mevalonate (Liver) [22] and High effects on the human enzymes:

hFPPS (Farnesyl pyrophosphate synthase) and hGGPPS (Geranylgeranyl pyrophosphate synthase).

\subsection{Prevention of Treatment-Induced Bone Loss}

The potential benefit of bisphosphonates to prevent the bone loss caused by endocrine therapy in breast and prostate cancer has previously been reviewed (Fig. 8) [23] while Fig. 9 displays the effect and benefits of applying BPs in oncology

In summary, ADT (androgen-deprivation therapy) in prostate cancer patients leads to a clinically significant bone loss that translates into a higher fracture risk at 5 years of $19.4 \%$, compared with $12.6 \%$ in nonusers ( $p$ $<$.001) [24]. Placebo-controlled trials have shown that pamidronate (60 mg i.v. every 3 months) can maintain BMD (bone mineral density) in patients $(n=43)$ with nonmetastatic prostate cancer receiving a gonadotropin-releasing hormone agonist, and that oral alendronate (70 $\mathrm{mg}$ once weekly) not only prevents bone loss but actually improves BMD in patients $(n=$ 112) on ADT (Figs. 10 and 11) [25]. However, zoledronic

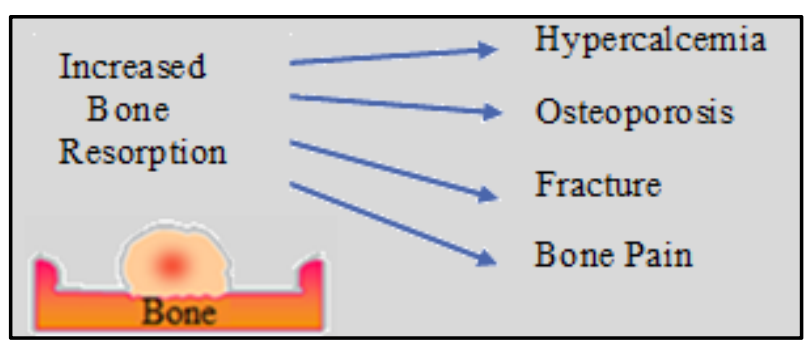

Fig. 7 Consequences of increased bone resorption.

Table 1 Clinic importance and prognosis of bone metastases (NCI, USA, 1913; Int. Myeloma Foundation).

\begin{tabular}{llll}
\hline $\begin{array}{l}\text { U.S. Disease } \\
\text { Prevalence }\end{array}$ & & $\begin{array}{l}\text { Bone Mets } \\
\text { Incid. (\%) }\end{array}$ & $\begin{array}{l}\text { Median } \\
\text { Survival }\end{array}$ \\
\hline Myeloma & $75-100$ & $70-75$ & 24 \\
Renal & 198 & $20-25$ & 12 \\
Melanoma & 467 & $14-45$ & 6 \\
Bladder & 582 & 40 & $6-9$ \\
Thyroid & 257 & 60 & 48 \\
Lung & 368 & $30-40$ & 7 \\
Breast & 893 & $65-75$ & 24 \\
Prostate & 684 & $65-75$ & 36 \\
\hline
\end{tabular}

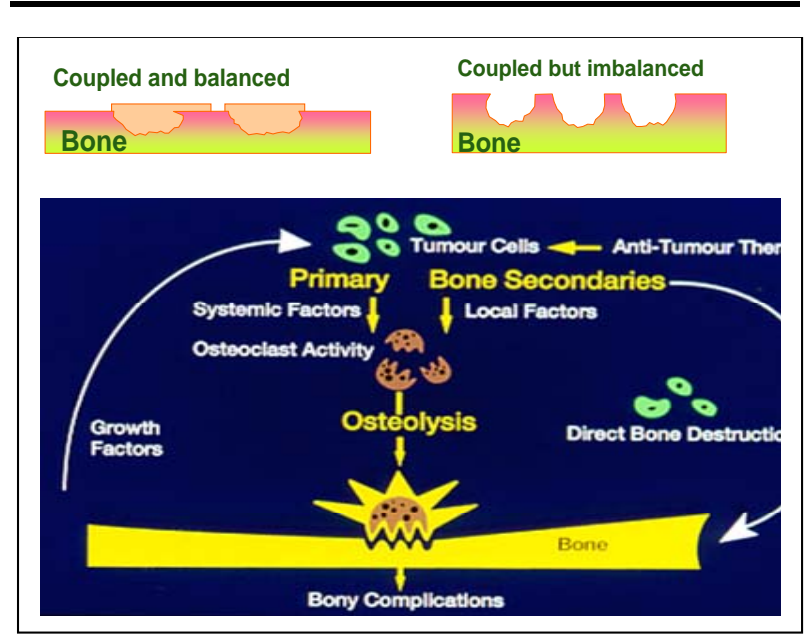

Fig. 8 Bone metastases. 


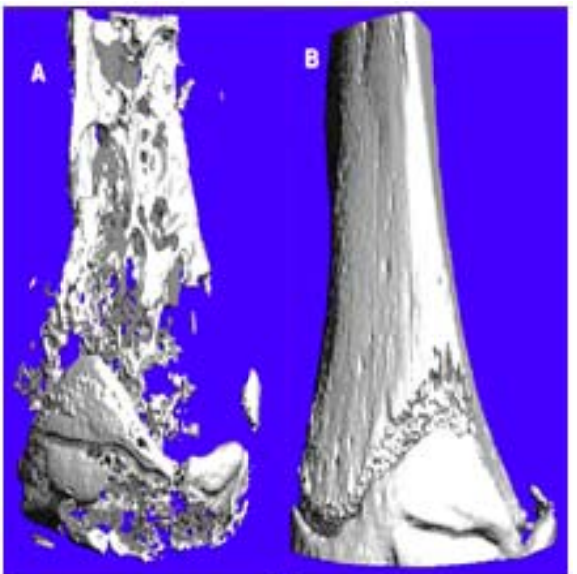

Fig. 9 The effect and benefits of applying BPs in oncology. (A) MicroCT image of the right tibia of the rat 6 weeks following intratibial injection of PC-3 human prostate cancer cells with bone lytic properties; (B) MicroCT image of the right tibia of the same nude rat, treated with BPs for 8 weeks.

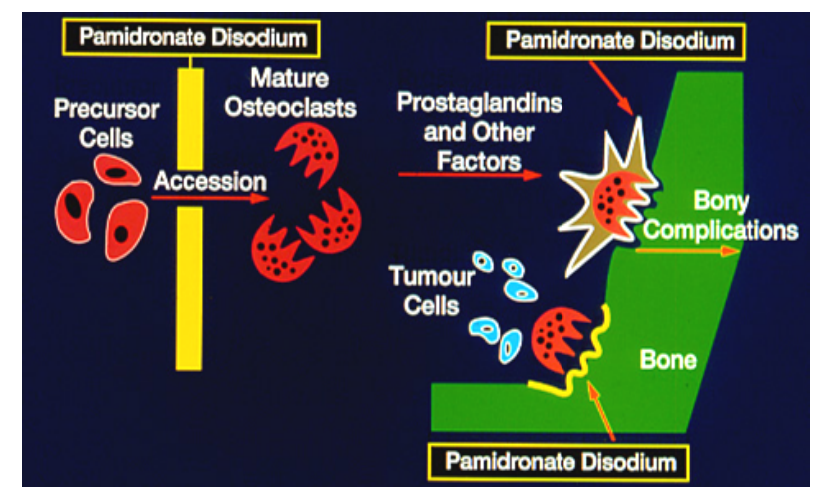

Fig. 10 Proposed mode of action of BPs in bone metastases.

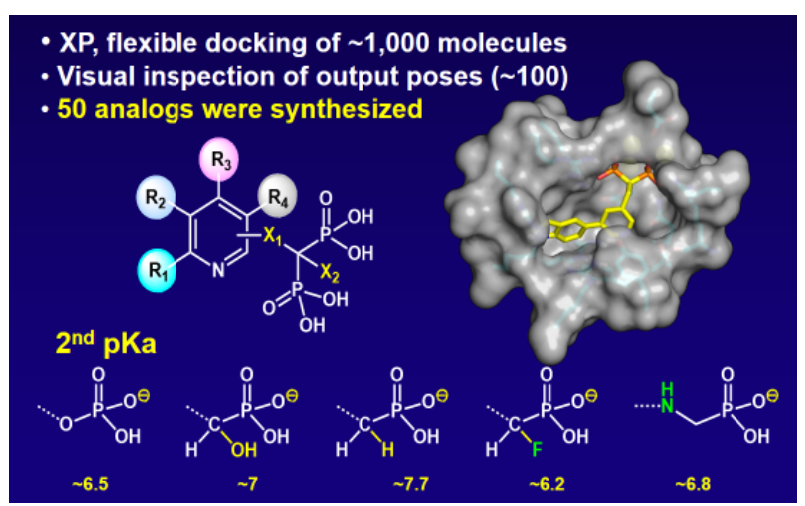

Fig. 11 In silico screening for hFPPS Inhibitor.

acid (4 mg i.v. once or every 3 months) currently has the most impressive bulk of evidence, with four published randomized controlled trials $(n=439)$ consistently demonstrating an increase in BMD, even after a single administration [26].
Likewise, breast cancer patients with chemotherapy-induced ovarian failure or receiving aromatase inhibitor treatment have a greater annual bone loss that results in a higher fracture incidence (11\%) than in patients treated with tamoxifen (8\%) [27]. Previous studies into the benefit of bisphosphonate treatment in these patients have shown that the oral bisphosphonates clodronate $(n=148)$; risedronate $(n=$ 53) can reduce this bone loss, but not completely prevent it [28]; and zoledronic acid, with three randomized trials $(n=2,068)$. Moreover, in postmenopausal women with early-stage breast cancer receiving letrozole, upfront zoledronic acid prevents bone loss more effectively than when treatment is delayed until bone loss has been documented [29].

\subsection{Current Evidence Supporting the Use of Bisphosphonates in Multiple Myeloma}

The older non-nitrogen-containing clodronate and the more potent BPs pamidronate, ibandronate, and zoledronic acid have been studied in multiple myeloma. Two large, placebo-controlled trials with oral clodronate are of interest, next to a larger number of smaller and mostly uncontrolled studies. One trial, using 2,400 mg/day for 24 months $(n=350)$, concluded a $50 \%$ proportional lower number of patients with progression of osteolytic bone lesions (24\% versus $12 \% ; p=0.026)$ and found more patients attaining a pain-free state. Patients in the second placebo-controlled clodronate trial $(n=536)$ received $1,600 \mathrm{mg} /$ day and showed, at 1 year, a $50 \%$ lower occurrence of severe hypercalcemia ( $5 \%$ versus $10 \% ; p$ $=0.06)$ and number of reported nonvertebral fractures (6.8\% versus $13.2 \% ; p=0.04)$ [30]. In contrast, only one placebo-controlled trial has been conducted with i.v. pamidronate (90 $\mathrm{mg} 4$ weekly) in stage III multiple myeloma patients $(n=392)$ with at least one osteolytic lesion, showing, at 9 months, a significantly lower proportion of patients with an SRE (24\% versus $41 \%$; $p$ $<0.001$ ) and a lower mean number of SREs per year (1.1 versus $2.2 ; p=0.0006$ ). However, a subsequent 
placebo-controlled study with oral pamidronate (300 $\mathrm{mg} /$ day) demonstrated no significant effect on SREs, presumably because of its very low and variable bioavailability.

In addition to a randomized phase II dose-seeking comparison with pamidronate $(n=280)$ demonstrating equal efficacy, the results of one randomized phase III trial $(n=518)$, showing the noninferiority of zoledronic acid versus pamidronate, form the basis for the use of this potent bisphosphonate in multiple myeloma. Both trials recruited a mixed population of breast cancer and stage III multiple myeloma patients. Finally, a large phase III trial with i.v. ibandronate ( $2 \mathrm{mg}$ monthly) was negative, with no difference in bone morbidity or survival in stage II/III multiple myeloma patients [31].

\subsection{Breast Cancer}

In addition to inhibiting bone resorption, bisphosphonates have also been shown to exhibit antitumor effects. In vitro, bisphosphonates inhibit proliferation and induce apoptosis in cultured human breast cancer cells. In addition, bisphosphonate treatment interferes with breast cancer cell adhesion to bone matrix, and inhibits cell migration and invasion. The combination of bisphosphonates with other anticancer drugs such as the taxoids markedly enhances these effects. These newly recognized direct actions of bisphosphonates on breast cancer cells indicate that these agents may have a greater role to play in treatment of patients suffering from cancers with a propensity to metastasize to bone.

Over $80 \%$ of women with advanced breast cancer ultimately develop bone metastases that result in significant morbidity and mortality. Breast cancer metastases in bone can cause intractable pain, bone fracture, spinal cord compression and hypercalcemia [21]. From the moment breast cancer cells arrive in the bone microenvironment, however, they stimulate bone resorption with subsequent selective increase in the attraction and growth of new cancer cells to bone [29]. Therefore, any treatment aimed at palliation or perhaps even prevention of bone metastases should focus on disrupting this attraction and growth, which are involved in the initiation and amplification of the metastatic process.

\subsubsection{Overview of Breast Cancer Correlation with} BPs

In addition to inhibiting bone resorption, BPs have also been shown to exhibit antitumor effects. In vitro, BPs inhibit proliferation and induce apoptosis in cultured human breast cancer cells. At least $25 \%$ of patients with breast cancer develop skeletal metastases. The introduction of BPs in oncology has dramatically changed the management of patients with metastatic bone disease. BPs have been proved to be the drugs of choice to: (a) decrease bone resorption in tumor bone disease; (b) the therapy induces a diminution of bone resorption; (c) leading to a decrease in hypercalcemia; (d) a decrease of new osteolytic lesions and a decrease of fractures; and leading to an amelioration of pain and an improvement of the quality of life (Fig. 12).

Little new research has been performed in the last decade in the setting of bone metastatic breast cancer, with major research groups focusing on adjuvant bisphosphonate therapy instead. In metastatic disease, early evidence from three placebo-controlled trials (total $n=417)$ suggests that oral clodronate $(800$ $\mathrm{mg} /$ day or $1,600 \mathrm{mg} /$ day) resulted in a significantly lower number/rate of skeletal events (hazard ratio [HR], 0.84; 95\% confidence interval [CI], 0.72-0.98), longer time to first SRE, lower incidence of vertebral fractures and deformity, and lower total number of (terminal) hypercalcemic episodes, and leads to less pain and a lower use of analgesics (Fig. 12) [32].

2.4.2 Overview of the Benefit of Treatment with BPs Placebo on the Risk of a Skeletal-Related Event in Bone Metastatic Breast Cancer

(Pooled data for clodronate and pamidronate are taken from a Cochrane review by Pavlakis et al. [32])

However, the methodology used in one of these studies may have overestimated treatment effects [32], the subsequent availability of more robust data 


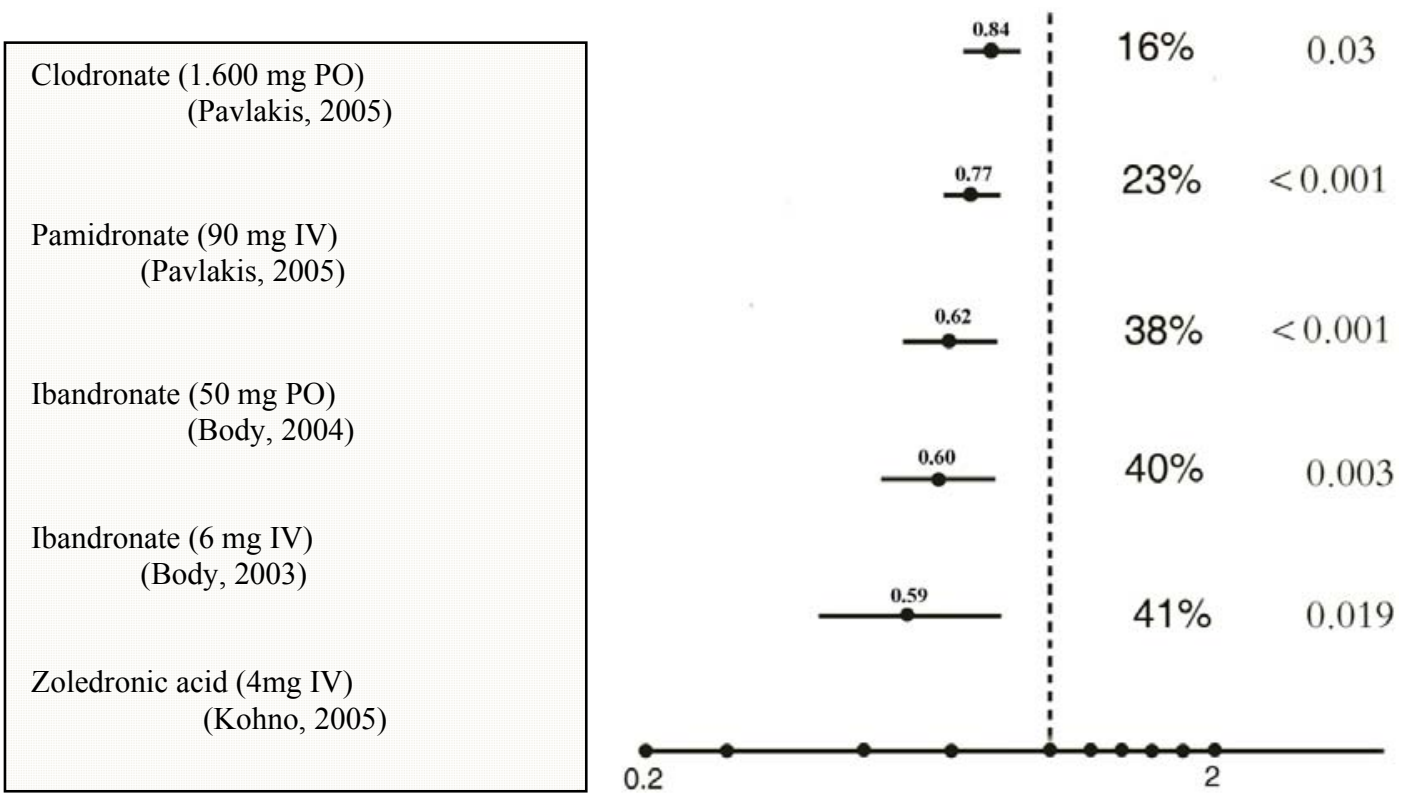

Fig. 12 The role of BPs in breast cancer.

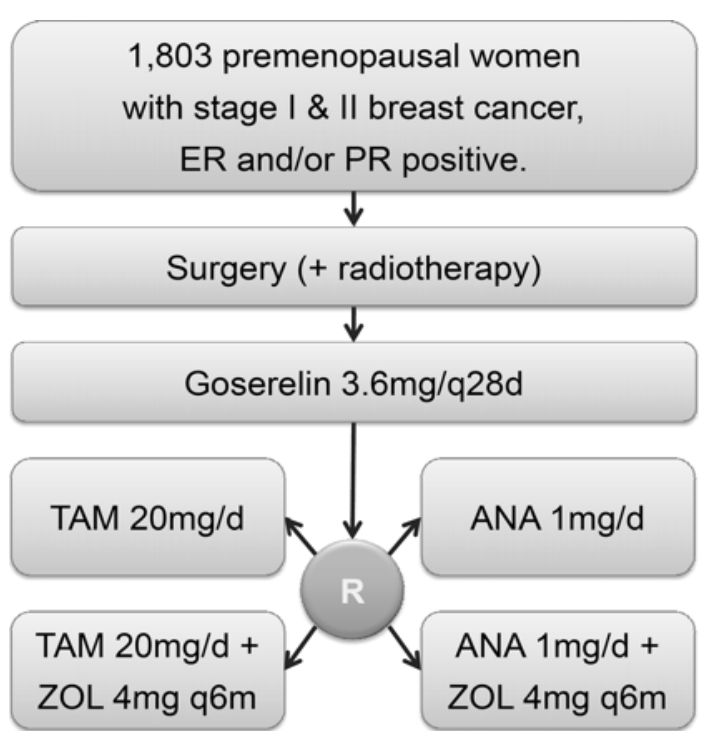

Fig. 13 Design of the Austrian Breast and Colorectal Cancer Study Group Trial 12 that recruited 1,803 premenopausal women between 1999 and 2006 with stage I or II and ER- and/or PR-positive breast cancer. All patients were chemotherapy naive, except for neoadjuvant treatment.

Abbreviations: ANA, anastrozole; ER, estrogen receptor; PR, progesterone receptor; q28d, every 28 days; q6m, every 6 months; TAM, tamoxifen; ZOL, zoledronic acid; PO, orally.

demonstrating similar activity of pamidronate, and the lack of U.S. Food and Drug Administration approval in the U.S. have all contributed to the rather limited use of clodronate in these patients [33]. Indeed, four placebo-controlled trials $(n=1,453)$ concluded that i.v. pamidronate (45-90 mg 3-4 weekly) results in a significantly longer time (12.7 versus 7.0 months; $p<$ 0.001 ) to the occurrence of the first SRE (HR, 0.77; 95\% CI, 0.69-0.87), lower incidence of SREs (53\% versus $68 \% ; p<0.001$ ), and longer time to progression of bone lesions ( 8.3 versus 5.6 months; $p=0.02$ ) [32, 34]. Moreover, evidence from a head-to-head comparison suggests its superiority over clodronate in both controlling symptoms and suppressing bone resorption [35]. The most recent data available are on the newer BPs zoledronic acid and ibandronate [12]. Besides the previously cited phase II trial in a mixed population of breast cancer and multiple myeloma patients, the firm body of evidence supporting zoledronic acid comes from both a positive placebo-controlled trial $(n=228)$ and a phase III noninferiority head-to-head comparison with pamidronate in patients with predominantly breast cancer $(n=1,130)$ (Fig. 13) [36]. At one year of follow-up and excluding hypercalcemia of malignancy, zoledronic acid resulted in a $20 \%$ lower percentage of patients with at least one SRE (30\% versus $50 \%$; $p=$ $0.003), 39 \%$ lower rate of SREs $(p=0.027)$, longer median time to first SRE (median, not reached versus 12 months; $p=0.007$ ), and $41 \%$ lower risk for SREs in 
a multiple-event analysis (HR, 0.59; 95\% CI, 0.37-0.91; $p=0.019$ ), compared with placebo [36]. Furthermore, zoledronic acid was found to provide a $20 \%$ additional lower risk for skeletal events (HR, 0.80; 95\% CI, 0.65-0.98; $p=0.037$ ) compared with pamidronate (multiple-event analysis), and even greater benefit in patients with at least one osteolytic lesion. Additional evidence suggesting the superiority of zoledronic acid comes from a phase II study showing that zoledronic acid, used as a salvage therapy in patients failing clodronate or pamidronate, can significantly improve pain control.

The oral and i.v. use of ibandronate has been studied in three placebo-controlled trials, all using a primary efficacy parameter that hampers comparison of the results with other studies. The SMPR (skeletal morbidity period rate) was defined as the number of 12-week periods with new bone complications divided by the number of periods on study, and excluding SREs that occurred during the first 12 weeks.

The i.v. trial (MF4265) randomized 466 patients to ibandronate (2 mg or $6 \mathrm{mg}$ ) or placebo every 3-4 weeks for up to 2 years. Only the group receiving $6 \mathrm{mg}$ showed a statistically significant advantage in terms of the SMPR ( $p=0.004)$, the number of new bone events, and the time to first event [37]. The efficacy of oral ibandronate was reported in a pooled analysis of two smaller phase III trials (MF4434 and MF4414) randomizing patients with bone metastases from breast cancer to $50 \mathrm{mg} /$ day ibandronate $(n=287)$ or placebo $(n=277)$ for up to 96 weeks. It concluded that ibandronate produced a significantly lower mean SMPR (0.95 versus $1.18 ; p=0.004)$, lower risk for a skeletal event (HR, 0.62; 95\% CI, 0.48-0.79; $p=$ $0.0001)$, lower mean number of events requiring radiotherapy ( 0.73 versus $0.98 ; p<0.001)$, and fewer events requiring surgery $(0.47$ versus $0.53 ; p=0.037$ ) [38].

However, the difference in the proportion of patients with an SRE, which is a straightforward and conservative endpoint that is considered statistically more rigorous for assessing the clinical benefit of bisphosphonate therapy, was not significant in the i.v. trial $(51 \%$ versus $62 \% ; p=0.052)$ and was not reported in the oral trial. Therefore, the results of two ongoing phase III trials comparing ibandronate with zoledronic acid are eagerly awaited [39].

\subsection{Prostate Cancer}

In patients with prostate cancer, the effect of clodronate on bone metastasis-free survival in the nonmetastatic setting and bone pain and bone progression-free survival in metastatic disease has been well studied. Although the results from smaller uncontrolled trials had been encouraging, all large controlled studies, with a total of 1,214 patients randomized, have reported negative findings (Table 2) [40]. Similarly, a randomized, prospective, double-blind, placebo-controlled study $(n=57)$ with i.v. etidronate followed by oral maintenance therapy in patients with hormone-refractory metastatic prostatic cancer showed no significant difference in pain control between the two groups.

In the treatment and prevention of SREs, pamidronate has been prospectively evaluated with disappointing results as well. A pooled analysis of two multicenter, double-blind, randomized, placebo-controlled trials $(n=378)$ in hormone-refractory prostate cancer patients with bone metastases failed to demonstrate an overall treatment benefit of 3-weekly i.v. pamidronate $(90 \mathrm{mg})$ on self-reported pain measurements, analgesic use, proportion of patients with an SRE, or mobility (Table 2) [41].

Treatment with 3-weekly i.v. zoledronic acid (4 mg), on the other hand, has effectively demonstrated a benefit in hormone-refractory prostate cancer patients with metastatic bone disease. In a large prospective, randomized, controlled trial $(n=422)$, there was a significant absolute $11 \%$ lower proportion of patients who experienced one or more SREs $(p=0.028)$ and a significantly longer time until the first SRE of 5.5 months 
Table 2 Overview of randomized, placebo-controlled trials evaluating the benefit of clodronate in prostate cancer.

\begin{tabular}{|c|c|c|c|c|c|}
\hline Study & $n$ & HRPC & Bone Metastases & Intervention & Primary endpoint and result \\
\hline Mason et al. [42] & 508 & No & No & Clodronate, $2,080 \mathrm{mg} /$ day PO & $\begin{array}{l}\text { Bone metastases-free survival: } \mathrm{HR} \\
1.22 ; 95 \% \mathrm{Cl}, 0.88-1.68: p=.23\end{array}$ \\
\hline Dearnaley et al. [43] & 311 & No & Yes & Clodronate, 2,080 mg/day PO & $\begin{array}{l}\text { Bone progression-free survival: } \mathrm{HR} \text {, } \\
0.79 ; 95 \% \mathrm{Cl}, 0.61-1.02 ; p=.06\end{array}$ \\
\hline Ernst et al. [44] & 209 & Yes & Yes & Clodronate, $1,500 \mathrm{mg} / 3$ wks i.v. & $\begin{array}{l}\text { Pain score reduction: response in } 45 \% \\
\text { versus } 39 \% ; p=.54\end{array}$ \\
\hline Kylmala et al. [45] & 56 & Yes & Yes & $\begin{array}{l}\text { Clodronate, } 300 \mathrm{mg} / \text { day i.v. } 5 \text { days, } \\
\text { then } 1,600 \mathrm{mg} / \text { day PO } 12 \mathrm{mos}\end{array}$ & $\begin{array}{l}\text { Pain intensity using VAS: no } \\
\text { significant difference in VAS at } 1,3 \text {, } \\
6 \text {, or } 12 \text { mos }\end{array}$ \\
\hline Strang et al. [46] & 55 & Yes & Yes & $\begin{array}{l}\text { Clodronate, } 300 \mathrm{mg} / \mathrm{d} \text { i.v. } 3 \text { days, } \\
\text { then } 3,200 \mathrm{mg} / \text { day PO } 3 \mathrm{wks}\end{array}$ & $\begin{array}{l}\text { Pain intensity using VAS; } 21 \mathrm{~mm} \\
\text { difference in VAS; } p>.05\end{array}$ \\
\hline Elomaa et al. [47] & 75 & Yes & Yes & $\begin{array}{l}\text { Clodronate, } 3,200 \mathrm{mg} / \text { day PO } 1 \mathrm{mo} \text {, } \\
\text { then } 1,600 \mathrm{mg} / \text { day PO }\end{array}$ & $\begin{array}{l}\text { Proportion of patients with pain: no } \\
\text { significant difference between groups } \\
\text { at } 1,3 \text {, or } 6 \text { mos }\end{array}$ \\
\hline
\end{tabular}

Abbreviations: CI, confidence interval; HR, hazard ratio; HRPC, hormone-refractory prostate cancer; PO, orally; VAS, visual analogue scale.

$(p=0.009)$. In addition, an absolute lower mean skeletal morbidity rate of 0.7 SREs per year $(p=0.005)$ was observed, compared with the placebo group in which at 2 years of follow-up $49 \%$ of patients experienced one or more SREs and had on average 1.47 SREs per year [48]. Looking beyond first-event analyses, zoledronic acid also resulted in a $36 \%$ lower ongoing relative risk for SREs (HR, 0.64; 95\% CI, $0.43-0.81 ; p=0.002$ ), compared with placebo. Interestingly, patients without pain appeared to benefit most, and therefore treatment with zoledronic acid should probably not be postponed until symptoms develop [49]. Data on ibandronate, the latest addition in the constellation of the bisphosphonates, are still maturing, and placebo-controlled trials are required before it can be considered [50].

\subsection{Other Solid Tumors}

Data on the efficacy of zoledronic acid in small cell and non-small cell lung cancer, renal cell carcinoma, and a variety of other histologies (including head and neck, thyroid, and unknown primary cancer) are derived from a large $(n=773)$, placebo-controlled trial demonstrating a significantly lower proportion (39\% versus $48 \% ; p=0.04$ ) of patients with an SRE (HR, 0.69; 95\% CI, 0.54-0.89; $p=0.003$ ), a longer median time to first SRE (7.9 versus 5.2 months; $p=$ 0.009 ), and a $36 \%$ lower annual incidence of SREs (mean, 1.74 versus 2.71 SREs per year; $\mathrm{p}=0.01$ ), compared with placebo at 21 months of follow-up [51]. A subset analysis of renal cell carcinoma patients in that trial was in agreement with this, with a significantly lower proportion $(37 \%$ versus $74 \% ; \mathrm{p}=$ 0.015 ) of patients with an SRE (HR, 0.39; 95\% CI, $0.19-0.81 ; p=0.008)$ [52]. The whole of these data has led to zoledronic acid being the only bisphosphonate to have worldwide regulatory approval for use in patients with bone metastases secondary to solid tumors other than breast cancer. Moreover, a randomized phase III study recruiting patients $(n=$ 287) with a broad range of malignancies demonstrated the superiority of zoledronic acid over pamidronate in the treatment of hypercalcemia [53].

\section{Risk Stratification Using Bone Turnover Markers}

When bone is resorbed by osteoclast activity, the collagen remnants of the organic matrix can be detected in the serum or urine $[54,55]$. These degradation products, including the amino-terminal (NTX-I) and carboxy-terminal (CTX-I) cross linked telo-peptide, have been shown to be specific biochemical markers of osteoclast function and hence of bone turnover [56]. Although initially used in clinical trials to assess the effect of bisphosphonate therapy on bone turnover, the use of serum CTX-I has recently been proposed to 
predict the risk for ONJ after an invasive dental procedure in patients receiving oral bisphosphonate therapy. Patients with morning fasting serum CTX-I levels $>150 \mathrm{pg} / \mathrm{ml}$ are considered to have adequate residual bone remodeling capacity and to be only at minimal risk [57].

However, the technique is subject to considerable variability, both subject and assay related, and most patients on bisphosphonate therapy will not have had a baseline CTX-I measurement. Moreover, known sources of CTX-I variability include, amongst others, the circadian cycle, gender, age, food intake, renal and liver function, and concomitant medication use [58]. Therefore, it can be questioned whether an arbitrarily defined cutoff of $150 \mathrm{pg} / \mathrm{ml}$ that does not take into account pre-therapy baseline CTX-I levels is universally appropriate. In fact, recently published reports cast doubt on the reliability of CTX-I by failing to demonstrate a significant relationship between the marker and the severity of ONJ and the fact that some patients with ONJ have bone markers that are within the normal range $[59,60]$.

In patients with skeletal metastases, the theoretical merit of bone turnover markers is lacking, and they should thus not be used to guide clinical management decisions. Indeed, bone markers give an overall impression of bone turnover in the whole skeleton, and in cancer patients this will largely be determined by the number and activity of metastatic tumor deposits in the skeleton. A serum CTX-I sample with a value above a predefined threshold is, in these patients, not a measure of adequate residual osteoclast capacity, but rather of poor disease control.

In addition, the increase in bone turnover markers caused by skeletal metastases varies greatly among different malignancies. This was elegantly demonstrated in a pooled analysis of three randomized, controlled, phase III clinical trials of cancer patients ( $n$ $=1,462)$ receiving zoledronic acid. Approximately 44\% of prostate cancer patients had highly elevated urinary NTX-I/creatinine levels at baseline, compared with $37 \%$ of breast cancer patients and only $20 \%$ of multiple myeloma patients. Moreover, bone resorption markers have been found to provide prognostic information in patients with bone metastases. Persisting high or moderate NTX-I/creatinine levels in patients with solid tumors during bisphosphonate treatment were associated with a 4.8 -fold (95\% CI, 3.9-5.9; $p<.001)$ and 3.1-fold (95\% CI, 2.5-3.8; $p$.001) higher risk for death, respectively, compared with patients with low bone turnover markers [61]. Consequently, the use of marker-directed therapy is prospectively being investigated in the BISMARK (BPs in metastatic bone disease: marker directed therapy with zoledronic acid) trial [62].

In summary, although the theoretical concept of risk stratification using CTX-I in osteoporosis patients is appealing, the current evidence is still limited and requires further validation before its widespread clinical use is warranted. In contrast, in cancer patients with metastatic bone disease, who will ultimately represent $95 \%$ of ONJ cases, we see no role for bone markers to guide management decisions as yet.

\section{Chemistry}

\subsection{Synthesis}

The general formula of BPs allows a great number of possible variations, simply by changing the two lateral chains on the carbon. Small changes in $\mathrm{R}^{1}$ or $\mathrm{R}^{2}$ moiety can lead to extensive alterations in their physical, chemical, biological, therapeutical and toxicological properties (Fig. 14).

The CAMM (computer-assisted molecular modeling), PASS program [63, 64], was adopted for designing in silico - the structures of potentially active molecules for synthesis. However, synthesis of bisphosphonate derivatives and the relevant bisphosphonic acid was recently discussed in detail in a recent review article [65]. Therefore, we are herein present some of our new results obtained lately on developing new BPs as antineoplastic agents. 


\subsection{Synthesis of Some Anti-tumor BP-compounds}

Methylenebisphosponic acid tetraethyl ester (1) was added to 2-azido-2a,b, 6a-e and 2-chloroquinoline-3-chalcones 9a-d (Schemes 1-3) in boiling sodium ethanolate solution to give via condensation reaction (Scheme 1) or Michael addition (Schemes 2 and 3), tetrazolo[1, 5-a] quinoline- 4a,b, 7a-e and 2-chloroquinoline-based bisphosphonates 10a-d, in E-configuration. Further acid hydrolysis of selective BPs afforded the respective BP-acid analogues 5, 8, and 11 in excellent yields. Anti-tumor activity screening for the new BP-compounds at a dose of $10 \mu \mathrm{M}$ utilizing 44 different human tumor cell lines representing breast, ovary, prostate, lung, and CNS cancer as well as leukemia and melanoma was carried out. Eight of ten tested compounds exhibited remarkable anti-tumor activity against breast, and prostate cancer, and a promised anti-tumor sensitivity toward ovarian cancer and melanoma. Conversely, there was only scattered activity against leukemia; and no noticeable action of these BP-acids on CNS or lung cancer $[66,67]$.

A series of methylenediphosphonate compounds 18, 19 and 20 by conducting the condensation reaction of oxazines 12-17 (Fig. 15) with Horner reagent, tetraethyl methylenebisphosphonate reagent $\mathbf{1}$. Antitumor properties of bisphosphonate products of types 18-20 (Fig. 16) were discussed [68].

A general synthetic approach to two new series of BPs: arylamino-2-ethane-1,1-diyl- and benzoxazole-2-methylenebisphosphonates was recently reported [69] Acid hydrolysis of selected BPs was undertaken to give the corresponding bisphosphonic acid (BP-acid). Next, the prediction of the permeability (hydrophobicity) of the target compounds was measured, by a combination of RP-HPLC and computational techniques, to study the capacity of transporting the molecule through cellular membranes. Cytotoxicity/growth inhibition of $50 \%$ $\left(\mathrm{GI}_{50}, \mathrm{mg} / \mathrm{L}\right)$ properties of the products was evaluated. Later on, a comparison of the pharmacological results with water-octanol partition coefficients $\left(\log K_{\mathrm{OW}}\right)$ of the compounds was also discussed.

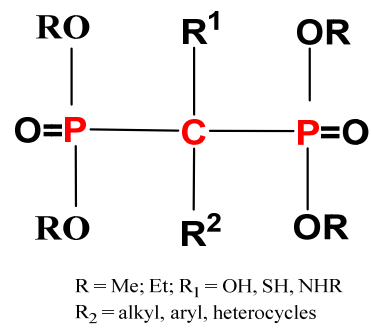

Fig. 14 General structure of BPs.

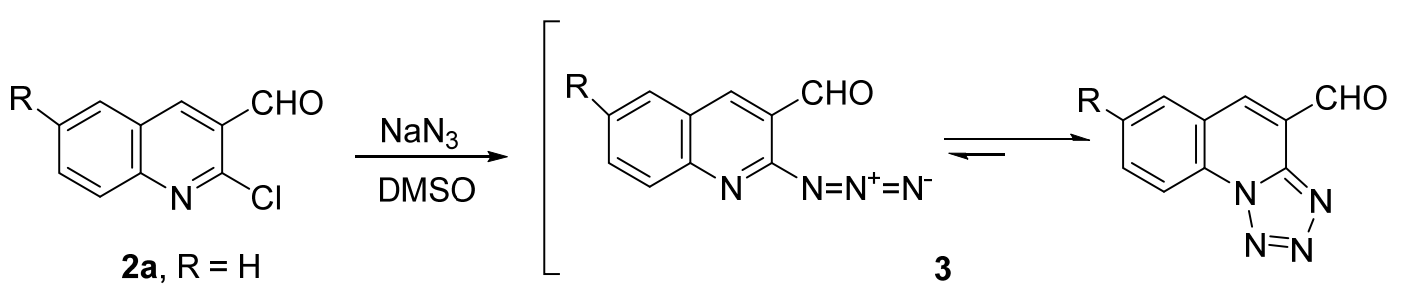

$2 \mathrm{~b}, \mathrm{R}=\mathrm{Me}$

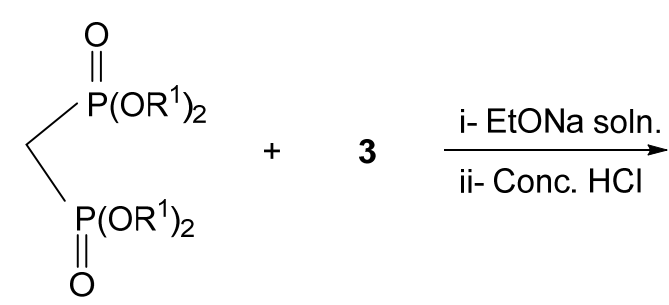

1, $\mathrm{R}^{1}=\mathrm{Et}$<smiles>[R2][R20]([R20])=O</smiles>

4, $R=H, R^{1}=E t$ (or H)

5, $R=M e, R^{1}=E t$ (or $\left.H\right)$

Scheme. 1 Synthesis of bisphosphonate derivatives. 
<smiles>[R]C(=O)/C([R])=C/c1cc2ccccc2n2nnnc12</smiles>

$+\mathrm{H}_{2} \mathrm{C}\left[\mathrm{P}(\mathrm{O})\left(\mathrm{OR}^{1}\right)_{2}\right]_{2}$

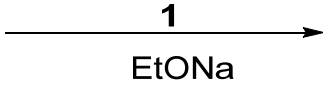

7a-d $\stackrel{\text { conc } \mathrm{HCl}}{\triangle}$ 8a-d

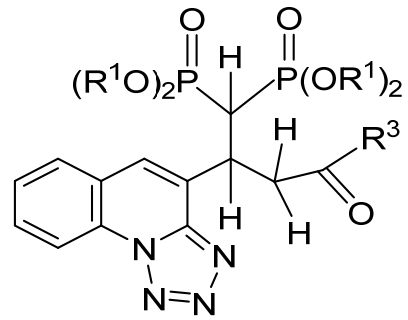

7a-d, $R^{1}=E t$ 8a-d, $R^{1}=H$

$$
\begin{array}{llllll}
\text { 7, 8 } & \mathrm{R}^{2} & \mathrm{R}^{3} & \mathbf{7 , 8} & \mathrm{R}^{2} & \mathrm{R}^{3} \\
\text { a } & \mathrm{H} & \mathrm{Ph} & \text { d } & \mathrm{H} & \text { 2-furanyl } \\
\text { b } & \mathrm{H} & \text { 2-thienyl } & \text { e } & \mathrm{CN} & \mathrm{NH}_{2} \\
\text { c } & \mathrm{H} & \text { 2-pyrrolyl } & & &
\end{array}
$$

Scheme. 2 Synthesis of tetrazolo-quinoline bisphosphonate derivatives.<smiles>[R]C(=O)/C([R])=C/c1cc2ccccc2nc1Cl</smiles>

9a-d

$\mathrm{R}^{2}, \mathrm{R}^{3}$ as in Scheme 2

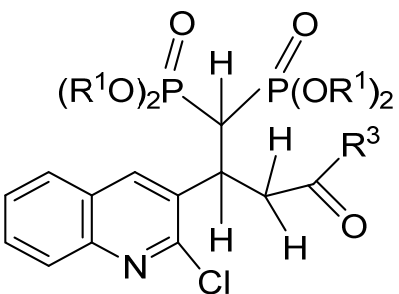

10a-d, $R^{1}=E t$

11a-d, $R^{1}=H$

Scheme. 3 Synthesis of chloroquinoline bisphosphonate derivatives.<smiles></smiles>

12,13a, $Z=P h$

b, $Z=M e$

c, $\mathrm{Z}=\mathrm{C}_{6} \mathrm{H}_{11}$

d, $Z=M e$<smiles>[Z]C1=Nc2ccccc2C(=S)S1=O</smiles>

14,15a, $Z=P h$

b, $Z=M e$

c, $Z=\mathrm{C}_{6} \mathrm{H}_{11}$

d, $Z=M e$<smiles>[Y]C1=NS(=O)C(=S)c2ccccc21</smiles>

16,17a, $\mathrm{Y}=4-\mathrm{CH}_{3} \cdot \mathrm{C}_{6} \mathrm{H}_{4}$ b, $\mathrm{Y}=4-\mathrm{OCH}_{3} \cdot \mathrm{C}_{6} \mathrm{H}_{4}$

c, $Y=\mathrm{C}_{6} \mathrm{H}_{5}$

d, $Y=4-\mathrm{NEt}_{2} \cdot \mathrm{C}_{6} \mathrm{H}_{4}$

Fig. 15 Structures 12-17.<smiles>[X]C1=C(C)C(C)N([R])C1([R]OCC)[R]OCC</smiles>

18

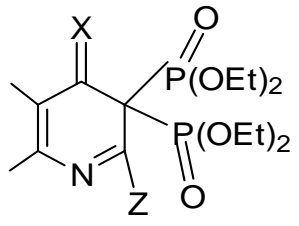

19<smiles>[X]C1=NC(P(=O)=O)([Pb](=O)OCC)C([X])=C(C)C1C</smiles>

20

$$
\begin{aligned}
& X=S \text { or } \mathrm{O} \\
& \mathrm{R}=\mathrm{H}
\end{aligned}
$$$$
\mathrm{X}=\mathrm{S} \text { or } \mathrm{O}
$$$$
Z=\mathrm{Ph}, Z=\mathrm{Me}
$$$$
\mathrm{Z}=\mathrm{C}_{6} \mathrm{H}_{11}, \mathrm{Z}=\mathrm{Me}
$$

$\mathrm{X}=\mathrm{S}$ or $\mathrm{X}$

$\mathrm{Y}=4-\mathrm{Me} \cdot \mathrm{C}_{6} \mathrm{H}_{4}, \mathrm{Y}=4$-OMe. $\mathrm{C}_{6} \mathrm{H}_{4}$ $\mathrm{Y}=\mathrm{Ph}, \mathrm{Y}=4-\mathrm{NEt}_{2} \cdot \mathrm{C}_{6} \mathrm{H}_{4}$

Fig. 16 Structures 18-20. 


\subsection{Anti-tumor Potency}

Antitumor activity screening of several BP- acids obtained in Schemes 1-4 was investigated in vitro applying a human breast (MCF7) h.cervix (HELA), h.colon (HCT116), and h.prostate (PC-3) carcinoma cell lines. 5-Fluoro-uracil drug was used as positive control. The results showed that the most effective BP-acids among the tested compounds are the structures A-D (Fig. 17) whereas the significant inhibition was displayed toward the breast cell line MCF7.
The obtained results represent concentration of the used investigated compounds resulting in growth inhibition of $50 \%\left(G I_{50} \mu \mathrm{mol} / \mathrm{mL}\right)$ for the tested human cell lines.

For example, concentrations result in growth inhibition of $50 \%\left(G I_{50}, \mathrm{mg} / \mathrm{L}\right)$ of in vitro human breast tumor cell lines (MCF7),

5-fluorouracil $G I_{50}: 17.7 \mu \mathrm{mol} \mathrm{L}{ }^{-1}$ to $38.8 \mu \mathrm{mol} \mathrm{L}^{-1}$; A $G I_{50}: 14.2$ to $30.9 \mu \mathrm{mol} \mathrm{L}{ }^{-1}$; B $G I_{50}: 15.6$ to 30.2 $\mu m o l L^{-1}$;

C $G I_{50}: 17.3$ to $32.6 \mu \mathrm{mol} \mathrm{L} L^{-1}$; $G_{50}: 17.5$ to 35.6 $\operatorname{mol} L^{-1}$.<smiles>[Y]C=Nc1cc(C(C)(C)C)cc(C(C)(C)C)c1O</smiles>

21a-d

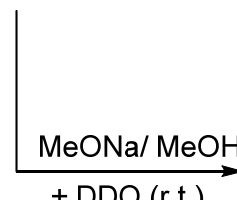

$+\mathrm{DDQ}$ (r.t.)<smiles>CCOP(=O)(CP(=O)=O)OCC</smiles><smiles>CCONC(=O)O</smiles>
1<smiles>[Y]C1(C(P(=O)=O)[P+](=O)OCC)Nc2cc(C(C)(C)C)cc(C(C)(C)C)c2O1</smiles>

f, $\mathrm{Y}=4-\mathrm{Cl}-\mathrm{C}_{6} \mathrm{H}_{4}$

g, $\mathrm{Y}=3-\mathrm{Cl}-\mathrm{C}_{6} \mathrm{H}_{4}$

h, $\mathrm{Y}=2-\mathrm{Cl}-\mathrm{C}_{6} \mathrm{H}_{4}$ i, $\mathrm{Y}=2,5-(\mathrm{MeO})_{2}-\mathrm{C}_{6} \mathrm{H}_{3}$

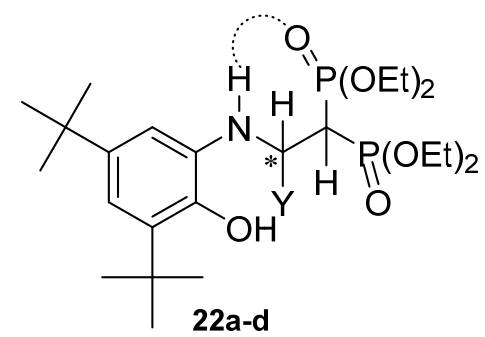
a, $\mathrm{Y}=4-\mathrm{MeO}-\mathrm{C}_{6} \mathrm{H}_{4}$
b, $\mathrm{Y}=4-(\mathrm{Me})_{2} \mathrm{~N}-\mathrm{C}_{6} \mathrm{H}_{4}$
c, $\mathrm{Y}=4-\mathrm{F}-\mathrm{C}_{6} \mathrm{H}_{4}$
d, $\mathrm{Y}=4-\mathrm{O}_{2} \mathrm{~N}-\mathrm{C}_{6} \mathrm{H}_{4}$

Scheme. 4 Synthesis of benzoxazole bisphosphonate derivatives.

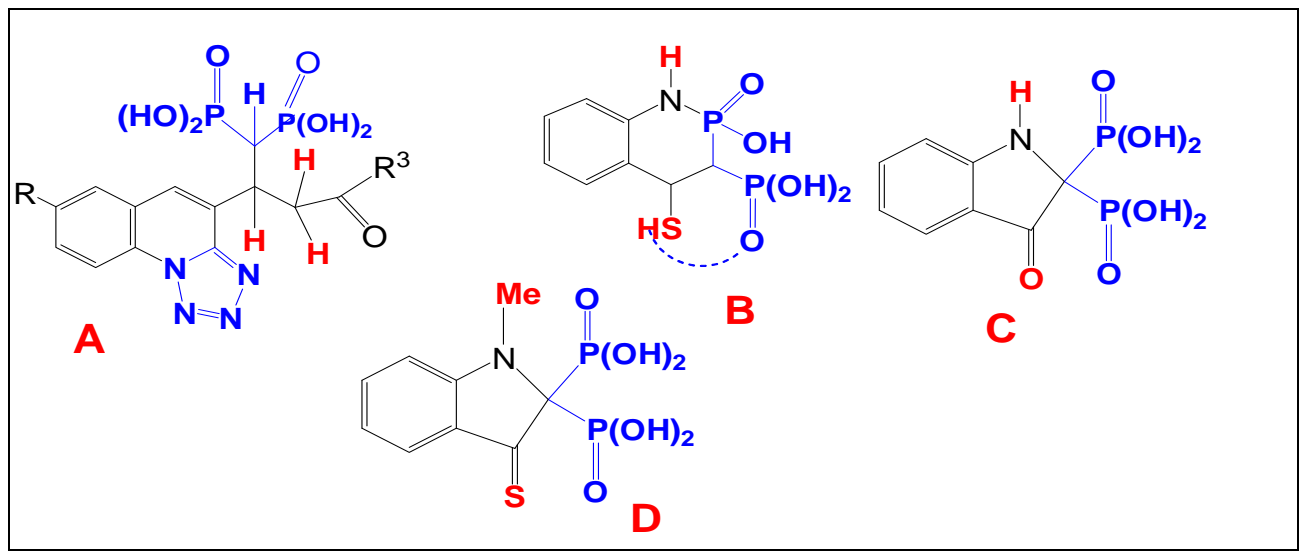

Fig. 17 Anti-tumor evaluation results.

Breast: (MCF7); cervix (HELA); colon (HCT116); prostate (PC-3). 


\section{Conclusion}

The bisphosphonates have been proven to be an important asset in the treatment and prevention of SREs in cancer patients with bone metastases. Although the results in the adjuvant setting are very promising, in particular in the prevention of bone metastases, they are as yet not practice changing. With the results of a number of large trials set to be reported in the near future, the final verdict on the adjuvant use of BPs in breast cancer is still out. Nonetheless, it seems reasonable to assume that some of this research will translate into new indications for BPs use in oncology. With the increasing use of bisphosphonates, ONJ has to be recognized as a potential side effect that is rare, but can have a high impact on quality of life. However, when implementing a set of straight-forward preventative measures, ONJ should not deter the clinician from using this powerful tool in daily practice and recognizing the rising stars that the BPs continue to be in oncology.

\section{Acknowledgment}

Authors like to thank the National Research Centre, Dokki, Cairo Egypt for financial support project \# 10010101.

\section{References}

[1] Fleisch, H., Russell, R. G. G., Bisaz, S., Casey, P. A., and MÜhlbauer, R. C. 1968. "The Influence of Pyrophosphate Analogues (Diphosphonates) on the Precipitation and Dissolution of Calcium Phosphate in vitro and in vivo." Calcif. Tissue Res. 2: 10-10a.

[2] Van den Wyngaert, T., Huizing, M. T, and Vermorken, J. B. 2008. "Disambiguating the Bisphosphonates." Ann. Oncol. 19: 1357-9.

[3] Bassett, C. A., Donath, A., Macagno, F., Preisig, R., Fleisch, H., and Francis, M. D. 1969. "Diphosphonates in the Treatment of Myositis Ossificans." Lancet. 294: 845.

[4] Fleisch, H., Russell, R. G., and Francis, M. D. 1969. "Diphosphonates Inhibit Hydroxyapatite Dissolution in vitro and Bone Resorption in Tissue Culture and in vivo." Science 165: 1260-2.

[5] Bijvoet, O. L. M., Fleisch, H., Canfield, R. E., and Russel, R. G. G. 1995. Bisphosphonates on Bones. Amsterdam,
Holland: Elsevier.

[6] Wang, L., Kamath, A., Daz, H., Li, L., and Bukowski, J. F. 2001. "Antibacterial Effect of Human V $\gamma 2$ V $\delta 2$ T Cells in vivo." J. Clin. Invest. 108: 1349-57.

[7] Wafaa, M. A., Abeer, A. S., Rizk, E. K., and Ghada, E. A. A. 2015. "Synthesis and Antimicrobial Evaluation of Newly Synthesized N,S-Bisphosphonate Derivatives." J. Heterocycl. Chem. Published online: 27 Apr 2015. DOI 10.1002/jhet.2306.

[8] Ghosh, S., Chan, J. M. W., Lea, C. R., Meints, G. A., Lewis, J. C., Tovian, Z. S., Flessner, R. M., Loftus, T. C., Bruchhaus, I., Kendrick, H., Croft, S. L., Kemp, R. G., Kobayashi, S., Nozaki, T., and Oldfield, E. 2004. "Effects of Bisphosphonates on the Growth of Entamoeba histolytica and Plasmodium Species in Vitro and in Vivo." J. Med. Chem. 47: 175-87.

[9] Cromartie, T. H., Fisher, K. J., and Grossman, J. N. 1999. "The Discovery of a Novel Site of Action for Herbicidal Bisphosphonates." Pest. Biochem. Phsol. 63: 114-26.

[10] Mckenna, C. E., Kashemirov, B. A., and Li, Z. M. 1999. "Synthetic Approaches to Biologically Active Bisphosphonates and Phosphonocarboxylates." Phosphorus, Sulfur and Silicon 144-146: 313-6.

[11] Shaddy, A. A., Kamel, A. A. and Abdou, W. M. 2013. "Synthesis, Quantitative Structure-Activity Relationship, and Anti-inflammatory Profiles of Substitued 5- and 6-N-Heterocycle Bisphosphonate Esters." Synth. Comm. 43: 236-52.

[12] Peng, Z. Y., Mansour, J. M., Araujo, F., Ju, J. Y., Mckenna, C. E., and Mansour, T. E. 1995. "Some Phosphonic Acid Analogs as Inhibitors of Pyrophosphate-Dependent Phosphofructokinase, a Novel Target in Toxoplasma Gondii." Biochem. Pharm. 49: 105-13.

[13] Fleisch, H. 1988. Bisphosphonates: A New Class of Drugs in Diseases of Bone and Calcium Metabolism, edited by Baker, P. F., Handbook of Experimental Pharmacology, Berlin/Heidelberg: Springer, 83: 441-65.

[14] Nakamura, M., Ando, T., Abe, M., Kumagai, K., and Endo, Y. 1996. "Contrast between Effects of Aminobisphosphonates and Non-aminobisphosphonates on Collagen-Induced Arthritis in Mice." Br. J. Pharmacol. 119: 205-12.

[15] Maksymowych, W. P. 2002. "Bisphosphonates: Anti-inflammatory Properties." Curr. Med. Chem.-Anti-Inflammatory \& Anti-Allergy Agents 1: 15-28.

[16] Fleisch, H. 2002. "The Role of Bisphosphonates in Breast Cancer: Development of Bisphosphonates." Breast Cancer Res. 4: 30-4.

[17] Mundy, G. R. 1997. "Mechanisms of Bone Metastasis." Cancer 80: 1546-56.

[18] Ross, J. R., Saunders, Y., Edmonds, P. M., Patel, S., Broadley, K. E., and Johnston, S. R. D. 2003. "Systematic 
Review of Role of Bisphosphonates on Skeletal Morbidity in Metastatic Cancer." BMJ 327: 469-74.

[19] Marx, R. E. 2003 "Pamidronate (Aredia) and Zoledronate (Zometa) Induced Avascular Necrosis of the Jaws: A Growing Epidemic.” J. Oral Maxillofac Surg. 61: 1115-7.

[20] Conte, P., and Guarneri, V. 2004. "Safety of Intravenous and Oral Bisphosphonates and Compliance with Dosing Regimens." The Oncologist 9: 28-37.

[21] Estilo, C. L., Van Poznak, C. H., Wiliams, T., Bohle, G. C., Lwin, P. T., Zhou, Q., Riedel, E. R., Carlson, D. L., Schoder, H., Farooki, A., Fornier, M., Halpern, J. L., Tunick, S. J., and Huryn, J. M. 2008. "Osteonecrosis of the Maxilla and Mandible in Patients with Advanced Cancer Treated with Bisphosphonate Therapy." The Oncologist 13: 911-20.

[22] Ibrahim, T., Barbanti, F., Giorgio-Marrano, G., Mercatali, L., Ronconi, S., Vicini, C., and Amadori, D. 2008. "Osteonecrosis of the Jaw in Patients with Bone Metastases Treated with Bisphosphonates: A Retrospective Study." The Oncologist 13: 330-6.

[23] Brufsky, A. M. 2008. "Cancer Treatment-Induced Bone Loss: Pathophysiology and Clinical Perspectives." The Oncologist 13: 187-95.

[24] Polascik, T. J. 2008. "Bone Health in Prostate Cancer Patients Receiving Androgen-Deprivation Therapy: The Role of Bisphosphonates." Prostate Cancer Prostatic Dis. 11: 13-9.

[25] Greenspan, S. L., Nelson, J. B., Trump, D. L., and Resnick, N. M. 2007. "Effect of Once-Weekly Oral Alendronate on Bone Loss in Men Receiving Androgen Deprivation Therapy for Prostate Cancer: A Randomized Trial." Ann. Intern. Med. 146: 416-24.

[26] Ryan, C. W., Huo, D., Demers, L. M., Beer, T. M., Lacerna, L. V. and the Zometa US05 Investigators. 2006. "Zoledronic Acid Initiated during the First Year of Androgen Deprivation Therapy Increases Bone Mineral Density in Patients with Prostate Cancer." J. Urol. 176: 972-8.

[27] McCloskey, E. 2006. "Effects of Third-Generation Aromatase Inhibitors on Bone." Eur. J. Cancer 42: 1044-51.

[28] Delmas, P. D., Balena, R., Confravreux, E., Hardouin, C., Hardy, P., and Bremond, A. 1997. "Bisphosphonate Risedronate Prevents Bone Loss in Women with Artificial Menopause Due to Chemotherapy of Breast Cancer: A Double-Blind, Placebo-Controlled Study." J. Clin. Oncol. 15: $955-62$.

[29] Gnant, M., Mlineritsch, B., Stoeger, H., Luschin-Ebengreuth, G., Heck, D., Menzel, C., Jakesz, R., Seifert, M., Hubalek, M., Pristauz, G., Bauernhofer, T., Eidtmann, H., Eiermann, W., Steger, G., Kwasny, W., Dubsky, P., Hochreiner, G., Forsthuber, E-P., Fesl, C., and
Greil, R. 2008. "Adjuvant Endocrine Therapy plus Zoledronic Acid in Premenopausal Women with Early-Stage Breast Cancer: 5-Year Follow-up of the ABCSG-12 Bone-Mineral Density Substudy." Lancet. Oncol. 9: 840-9.

[30] McCloskey, E. V., MacLennan, I. C. M., Drayson, M. T., Chapman, C., Dunn, J., and Kanis, J. A. 1998. "A Randomized Trial of the Effect of Clodronate on Skeletal Morbidity in Multiple Myeloma." Br J. Haematol 100: 317-25.

[31] Menssen, H. D., Sakalova', A., Fontana, A., Herrmann, Z., Boewer, C., Facon, T., Lichinitser, M. R., Singer, C. R. J., Euller-Ziegler, L., Wetterwald, M., Fiere, D., Hrubisko, M., Thiel, E., and Delmas, P. D., 2002. "Effects of Long-Term Intravenous Ibandronate Therapy on Skeletal-Related Events, Survival, and Bone Resorption Markers in Patients with Advanced Multiple Myeloma." $J$. Clin. Oncol. 20: 2353-9.

[32] Pavlakis, N., Schmidt, R. L., and Stockler, M. R. 2005. "Bisphosphonates for Breast Cancer." Cochrane Database Syst Rev. (3): CD003474.

[33] Coleman, R. E. 2005. "Bisphosphonates in Breast Cancer." Ann. Oncol. 16: 687-95.

[34] Lipton, A., Theriault, R. L., Hortobagyi, G. N., Simeone, J., Knight, R. D., Mellars, K., Reitsma, D. J., Heffernan, M., and Seaman, J. J. 2000. "Pamidronate Prevents Skeletal Complications and Is Effective Palliative Treatment in Women with Breast Carcinoma and Osteolytic Bone Metastases: Long Term Follow-up of Two Randomized, Placebo-Controlled Trials." Cancer 88: 1082-90.

[35] Jagdev, S. P. 2001. "Comparison of the Effects of Intravenous Pamidronate and Oral Clodronate on Symptoms and Bone Resorption in Patients with Metastatic Bone Disease.” Ann. Oncol. 12: 1433-8.

[36] Kohno, N., Aogi, K., Minami, H., Nakamura, S., Asaga, T., Iino, Y., Watanabe, T., Goessl, C., Ohashi, Y., and Takashima, S. 2005. "Zoledronic Acid Significantly Reduces Skeletal Complications Compared with Placebo in Japanese Women with Bone Metastases from Breast Cancer: A Randomized, Placebo-Controlled Trial." J. Clin. Oncol. 23: 3314-21.

[37] Body, J. J., Diel, I. J., Lichinitser, M. R., Kreuser, E. D., Dornoff, W., Gorbunova, V. A., Budde, M., and Bergström, B. 2003. "Intravenous Ibandronate Reduces the Incidence of Skeletal Complications in Patients with Breast Cancer and Bone Metastases." Ann. Oncol. 14: 1399-405.

[38] Body, J. J., Diel, I. J., Lichinitzer, M., Lazarev, A., Pecherstorfer, M., Bell, R., Tripathy, D., and Bergstrom, B. 2004. "Oral Ibandronate Reduces the Risk of Skeletal Complications in Breast Cancer Patients with Metastatic 
Bone Disease: Results from Two Randomised, Placebo-Controlled Phase III Studies.” Br. J. Cancer 90: 1133-7.

[39] Barrett-Lee, P. J., and Murray, N. 2006. "Zoledronic Acid versus Ibandronate Comparative Evaluation in Breast Cancer Patients with Bone Metastases: The NCRI ZICE Trial." Bone 38: 67.

[40] Berry, S. 2006. "The Use of Bisphosphonates in Men with Hormone-Refractory Prostate Cancer: A Systematic Review of Randomized Trials." Can. J. Urol. 13: 3180-8.

[41] Small, E. J., Smith, M. R., Seaman, J. J., Petrone, S., and Kowalski, M. O. 2003. "Combined Analysis of Two Multicenter, Randomized, Placebo-Controlled Studies of Pamidronate Disodium for the Palliation of Bone Pain in Men with Metastatic Prostate Cancer." J. Clin. Oncol. 21: 4277-84.

[42] Mason, M. D., Sydes, M. R., Glaholm, J., Langley, R. E., Huddart, R. A., Sokal, M., Stott, M., Robinson, A. C., James, N. D., Parmar, M. K. B., and Dearnaley, D. P. 2007. "Oral Sodium Clodronate for Nonmetastatic Prostate Cancer-Results of a Randomized Double-Blind Placebo-Controlled Trial: Medical Research Council PR04 (ISRCTN61384873)." J. Natl. Cancer Inst. 99: 765-76.

[43] Dearnaley, D. P., Sydes, M. R., Mason, M. D., Stott, M., Powell, C. S., Robinson, A. C. R., Thompson, P. M., Moffat, L. E., Naylor, S. L., and Parmar, M. K. B. 2003. "A Double-Blind, Placebo-Controlled, Randomized Trial of Oral Sodium Clodronate for Metastatic Prostate Cancer (MRC PR05 Trial)." J. Natl. Cancer Inst. 95: 1300-11.

[44] Ernst, D. S., Tannock, I. F., Winquist, E. W., Venner, P. M., Reyno, L., Moore, M. J., Chi, K., Ding, K., Elliott, C., and Parulekar, W. 2003. "Randomized, Double-Blind, Controlled Trial of Mitoxantrone/Prednisone and Clodronate versus Mitoxantrone/Prednisone and Placebo in Patients with Hormone-Refractory Prostate Cancer and Pain." J. Clin. Oncol. 21: 3335-42.

[45] Kylmala, T., Taube, T., Tammela, T. L., Risteli, L., Risteli, J., and Elomaa, I. 1997. "Concomitant i.v. and Oral Clodronate in the Relief of Bone Pain-A Double-Blind Placebo-Controlled Study in Patients with Prostate Cancer." Br. J. Cancer 76: 939-42.

[46] Strang, P., Nilsson, S., Brändstedt, S., Sehlin, J., Borghede, G., Varenhorst, E., Bandman, U., Borck, L., Englund, G., and Selin, L. 1997. "The Analgesic Efficacy of Clodronate Compared with Placebo in Patients with Painful Bone Metastases from Prostatic Cancer." Anticancer Res. 17: 4717-21.

[47] Elomaa, I., Kylmälä, T., Tammela, T., Viitanen, J., Ottelin, J., Ruutu, M., Jauhiainen, K., Ala-Opas, M., Roos, L., Seppänen, J., and Alfthan, O. 1992. "Effect of Oral Clodronate on Bone Pain. A Controlled Study in Patients with Metastatic Prostatic Cancer.” Int. Urol. Nephrol. 24: 159-66.

[48] Saad, F., Gleason, D. M., Murray, R., Tchekmedyian, S., Venner, P., Lacombe, L., Chin, J. L., Vinholes, J. J., Goas, J. A. and Chen, B. 2002. "A Randomized, Placebo-Controlled Trial of Zoledronic Acid in Patients with Hormone-Refractory Metastatic Prostate Carcinoma." J. Natl. Cancer Inst. 94: 1458-68.

[49] Saad, F. 2007. "Bisphosphonates Can Prevent Skeletal Complications of Malignant Bone Disease from Prostate Cancer and Renal Cell Carcinoma." Eur. Urol. 6: 683-8.

[50] Heidenreich, A., Elert, A., and Hofmann, R. 2002. "Ibandronate in the Treatment of Prostate Cancer Associated Painful Osseous Metastases." Prostate Cancer Prostatic Dis. 5: 231-5.

[51] Rosen, L. S., Gordon, D., Tchekmedyian, N. S., Yanagihara, R., Hirsh, V., Krzakowski, M., Pawlicki, M., de Souza, P., Zheng, M., Urbanowitz, G., Reitsma, D., and Seaman, J. 2004. "Long-Term Efficacy and Safety of Zoledronic Acid in the Treatment of Skeletal Metastases in Patients with Nonsmall Cell Lung Carcinoma and Other Solid Tumors: A Randomized, Phase III, Double-Blind, Placebo-Controlled Trial." Cancer 100: 2613-21.

[52] Lipton, A. 2003. "Zoledronic Acid Delays the Onset of Skeletal-Related Events and Progression of Skeletal Disease in Patients with Advanced Renal Cell Carcinoma." Cancer 98: 962-9.

[53] Major, P., Lortholary, A., Hon, J., Abdi, E., Mills, G., Menssen, H. D., Yunus, F., Bell, R., Body, J., Quebe-Fehling, E., and Seaman, J. 2001. "Zoledronic Acid Is Superior to Pamidronate in the Treatment of Hypercalcemia of Malignancy: A Pooled Analysis of Two Randomized, Controlled Clinical Trials.” J. Clin. Oncol. 19: 558-67.

[54] Papapoulos, S. E., and Cremers, S. C. 2007. "Prolonged Bisphosphonate Release after Treatment in Children." $N$. Engl. J. Med. 356: 1075-6.

[55] Fleisch, H. 1995. Bisphosphonates in Bone Disease. Second edition. New York: The Parthenon Publishing Group, 27.

[56] Calvo, M. S., Eyre, D. R., and Gundberg, C. M. 1996. "Molecular Basis and Clinical Application of Biological Markers of Bone Turnover." Endocr. Rev. 17: 333-68.

[57] Marx, R. E., Cillo, J. E. Jr., and Ulloa, J. J. 2007. “Oral Bisphosphonate-Induced Osteonecrosis: Risk Factors, Prediction of Risk Using Serum CTX Testing, Prevention, and Treatment." J. Oral Maxillofac. Surg. 65: 2397-410.

[58] Seibel, M. J. 2005. "Biochemical Markers of Bone Turnover: Part I: Biochemistry and Variability." Clin. Biochem. Rev. 26: 97-122. 
[59] Bagan, J. V., Jime'nez, Y., Go'mez, D., Sirera, R., Poveda, R., and Scully, C. 2008. "Collagen Telopeptide (Serum CTX) and Its Relationship with the Size and Number of Lesions in Osteonecrosis of the Jaws in Cancer Patients on Intravenous Bisphosphonates." Oral Oncol. 44: 1088-9.

[60] Lehrer, S., Montazem, A., Ramanathan, L., Pessin-Minsley, M., Pfail, J., Stock, R. G., and Kogan, R. 2008. "Normal Serum Bone Markers in Bisphosphonate-Induced Osteonecrosis of the Jaws." Oral Surg. Oral Med. Oral Pathol. Oral Radiol. Endod. 106: 389-91.

[61] Coleman, R. E., Major, P., Lipton, A., Brown, J. E., Lee, K. A., Smith, M., Saad, F., Zheng, M., Hei, Y. J., Seaman, J., and Cook, R. 2005. "Predictive Value of Bone Resorption and Formation Markers in Cancer Patients with Bone Metastases Receiving the Bisphosphonate Zoledronic Acid.” J. Clin. Oncol. 23: 4925-35.

[62] Lipton, A. 2006. "Biochemical Bone Markers in Breast Cancer." Cancer Treat Rev. 32: 20-2.

[63] Da Silva, C. H., Da Silva, V. B., Resende, J., Rodrigues, P. F., Bononi, F. C., Benevenuto, C. G., and Taft, C. A. 2010. "Computer-Aided Drug Design and ADMET Predictions for Identification and Evaluation of Novel Potential Farnesyltransferase Inhibitors in Cancer Therapy."J. Mol. Graph. Model. 28: 513-23;

[64] Lagunin, A. A., Lagunin, A. A., Gomazkov, O. A., Filimonov, D. A., Gureeva, T. A., Dilakyan, E. A., Kugaevskaya, E. V., Elisseeva, Y. E., Solovyeva, N. I., and Poroikov, V. V. 2003. "Computer-Aided Selection of Potential Antihypertensive Compounds with Dual Mechanism of Action." J. Med. Chem. 46: 3326-32.

[65] Abdou, W. M., and Shaddy, A. M. 2009. "The Development of Bisphosphonates for Therapeutic Uses, and Bisphosphonate Structure-Activity Consideration." Arkivoc 9: 143-82.

[66] Abdou, W. M., Khidre, R. E., and Kamel, A. A. 2012. "Elaborating on Efficient Anti-Proliferation Agents of Cancer Cells and Anti-inflammatory-Based N-Bisphosphonic Acids." Arch. Pharm. Chem. Life Sci. 345: 123-36.

[67] Abdou, W. M., Kamel, A. A., Khidre, R. E., Geronikaki, A., and Ekonomopoulou, M. T. 2012. "Synthesis of 5- and 6- $N$-Heterocyclic Methylenebisphosphonate Derivatives and Evaluation of their Cytogenetic Activity in Normal Human Lymphocyte Cultures." Chemical Biology \& Drug Design. 79: 719-30.

[68] Kamel, A. A., Geronikaki, A., and Abdou, W. M. 2012. "Inhibitory Effect of Novel S,N-Bisphosphonates on Some Carcinoma Cell Lines, Osteoarthritis, and Chronic Inflammation." Eur. J. Med. Chem. 51: 239-49.

[69] Abdou, W. M., Barghash, R. F., and Sediek, A. A. 2012. "Design of New Arylamino-2-Ethane-1,1-Diyl- and Benzoxazole-2-Methylene-Bisphosphonates vs Cytotoxicity and Chronic Inflammation Diseases. From Hydrophobicity Prediction to Synthesis and Biological Evaluation.” Eur. J. Med. Chem. 57: 362-72. 